\title{
Effect of Terminalia catappa Leaves Extract on Corrosion of Mild Steel using Response Surface Methodology
}

\author{
${ }^{*}$ A. O. Okewale, ${ }^{2}$ O. A. Adesina and ${ }^{3}$ B. H. Akpeji \\ ${ }^{* 1}$ Department of Chemical Engineering, Federal University of Petroleum Resources, Effurun, Delta State, Nigeria \\ 2Department of Chemical and Petroleum Engineering, Afe Babalola University, Ado - Ekiti, Ekiti State,Nigeria \\ 3Department of Industrial Chemistry, Federal University of Petroleum Resources, Effurun, Delta State, Nigeria
} [Corresponding author: E-mail: Okewale.akindele@fupre.edu.ng; $\mathbf{8}:+2348069365637]$

\section{ABSTRACT}

Effect of Terminalia catappa leaves (TCL) extract in inhibiting corrosion of mild steel was investigated. In order to obtain the maximum inhibition efficiency, optimization of the process variables affecting corrosion of mild steel was carried out using the Box - Behnken Design plan and desirability function of Response Surface Methodology (RSM). The three parameters - varied include; TCL concentration (inhibitor), immersion time, and temperature and there effects in corrosion inhibition were established. The optimum conditions predicted from the quadratic model were inhibitor's concentratrion $(0.39 \mathrm{~g} / \mathrm{l})$, exposure time $(8.68$ hours), and temperature $\left(36.06{ }^{\circ} \mathrm{C}\right.$ ) with the inhibition efficiency of $91.95 \%$. The data fitted well to the quadratic model which was validated. Adsorption of the extract's component on the mild steel was responsible for the inhibitory effect of the TCL extract.The results showed that $97.92 \%$ of the total variation in the inhibition efficiency of TCL can be connected to the variables studied.

Keywords: Mild steel, acid, Terminalia catappa, Corrosion, Response surface methodology (RSM).

\section{INTRODUCTION}

Alloys of metals and pure metals react chemically with aggressive medium (acid) to form a stable compound in which the loss of metal occurs. The formed compound is called corrosion product (rust) and metal surface becomes corroded (Umoren et al., 2016). Corrosion involves the movement of metal ions into the solution at active areas (anode), passage of electrons from the metal to an acceptor at less active areas (cathode), an ionic current in the solution and an electronic current in the metal. The cathodic process requires the presence of an electron acceptor such as oxygen or oxidizing agents or hydrogen ions (Bentiss et al., 2000; HukovicMetikos et al.,2002; Raja and Sethuraman, 2008).

Metals corrosion is main problems that need to be tackled for economic, safety, and environmental reasons. This can be reduced by using appropriate approaches which will in turn suppress, impede or totally halt the cathodic or anodic reactions or both (Raja and Sethuraman, 2009). Amongst the numerous techniques of controlling and preventing corrosion, the application of corrosion inhibitors, is becoming very prevalent in mitigating corrosion in chemical process industries. Majority of the inhibitors that have been proven to be effective are natural complexes that contain mainly atoms of nitrogen, sulphur, or oxygen in their compositions. The use of some of these inorganic inhibitors has been restricted since their production is frequently very expensive. They can be hazardous and poisonous to wildlife, human beings, aquatic, and as well as the environment. This has led to the pursuit of environmentally friendly corrosion inhibitors as a substitute to changing the inorganic and organic inhibitors that will promote ecological green ecosystem. These readily available alternative green corrosion inhibitors are non-hazardous, economical, and can be regenerated. These inhibitors have been found in different parts of plant extract (Okafor et al., 2008; Okafor et al., 2010, Oguzie, 2008, Umoren et al., 2016).

The use of plant products as corrosion inhibitors are justified by the phytochemical compounds 


\section{Okewale: Effect of Terminalia catappa Leaves Extract on Corrosion of Mild Steel using Response...}

present therein, with molecular and electronic structures bearing close similarity to those of conventional organic inhibitor molecules (Oguzie et al., 2010). Some researchers have reported the inhibitory effect of some plants extracts on mild steel corrosion. These plants are; Andrographis paniculata (Singh and Quraishi, 2010), Spirulina platensis (Kamal et al., 2012), Jasminum ndiflorum L. (Li et al., 2010), Bridelia retusa (Patela et al., 2010), Dacryodis edulis (Oguzie et al., 2010), aqueous extracts of mango, orange, passion fruit and cashew peels (da Rocha et al., 2010), Artemisia pallens (Kalaiselvi et al., 2010), Gongronema latifolium (Eddy and Odiongenyi, 2010), Murraya koenigii (Quraishi et al., 2010), Azadirachta indica (Sharma et al., 2010; Okafor et al., 2010), Garcinia kola and Cola nitida (Okafor, et al., 2007), rubber seed oil (Okewale and Olaitan, 2017), Sida acuta (Umoren et al., 2016), Kopsia singapurensis (Raja et al., 2010).

Statistical modeling and optimization are very vital process in design of experiment this is because it enables improvement in the system and as well as increase in the process efficiency without increase in cost on the process. The classical method of experimentation where by one factor is considered at a time is time consuming, very tedious, and this does not give complete effects of the variables/parameters on the process. It does not give the combined interactions between the physiochemical parameters and can also lead to misinterpretation of the results (Bas and Boyaci, 2007).

Response Surface Methodology (RSM) is a collection of statistical and mathematical techniques that are useful for analysis and modeling of engineering problems in which a response of interest is influenced by several parameters (Montgomery, 2001). RSM is used for designing experiments, building numerical models, evaluating the effects of variables, and searching for optimum combinations of factors (Okewale et al., 2015). This method enable researcher to know the interactive effect of the parameters on the process. Terminalia catappa is a large tropical tree in the leadwood tree family, Combretaceae. The tree has been spread widely by humans and the native range is uncertain. It has long been naturalized in a broad belt extending from Northern Australia and New Guinea through Southeast Asia and Micronesia into the Indian Subcontinent. Common names include Indian almond, Bengal almond, Singapore almond, Malabar almond, Tropical almond, Sea almond, Talisay tree, and Umbrella tree. The phytochemical screening carried out on Terminalia catappa extract revealed that it is a complex a mixture of many components like tannin, flavonoids, saponins, alkaloids, terpenoid, anthraquinone, cardiac glycosides, and phlobatanin. This work evaluate the effect of Terminalia catappa leaf extract as an inhibitor on corrosion of mild steel in acidic medium at $30^{\circ} \mathrm{C}$ using gravimetric method while RSM was employed to investigate the effects of the corrosion parameters like temperature, time of immersion, and concentration of inhibitor on the inhibition efficiency of the inhibitor on mild steel.

\section{MATERIALS AND METHODS Materials}

Terminalia catappa leaves (TCL) were obtained from Ugbomro Community in Effurun, Delta State, Nigeria. Mild steel was procured from accredited iron sheet dealer in Effurun and machined in Mechanical Workshop at Federal University of Petroleum Resources, Delta State. HANNA model pH - 211 (pH meter), Genlab oven model Mino/75/f (oven), weighing balance of model (BH - 600), and beakers, were employed for the corrosion study. Hydrochloric acid, acetone, and ethanol solutions used were of analytical grades and were Sigma Aldrich. Distilled water was procured from the Department of Chemical Engineering Laboratory, Federal University of Petroleum Resources, Effurun, Delta State, Nigeria for sample preparation and solutions. 


\section{Methods \\ Pre-treatment of Sample and Sample Characterization}

The samples were thoroughly washed thereafter, sun dried and pulverized into powdery form with the aid of laboratory blender. It was then sieved with a sieve of $420 \mu \mathrm{m}$ mesh. The sample was later stored in a desiccator prior to use.

\section{Analysis of the Phytochemical Constituents in Terminalia catappa Leaf Extracts}

Screening of the phytochemical constituents of Terminalia catappa leaf extractwere carried out to identify the chemical active constituents present in the Terminalia catappa leaf extract. The qualitative and quantitative methods were used as previously described (Okwu, 2001; Rahilla et al., 1994; Sofowora, 1993; and Harborne, 1973).

\section{$\mathrm{X}$ - ray Fluorescence Analysis (X - RF)}

The elemental compositions of the mild steel used were observed with $X$ - supreme 800 , Oxford instrument. The metal was machined to flat shape of $20-50 \mathrm{~mm}$ diameter. Sample cup was cleaned and filter fixed in it shape. Thereafter, the metal sample was placed in the cup to cover the filter and ensure a thickness of $3 \mathrm{~mm}$ at the bottom. The instrument was switched on, the elemental composition method was selected, and the sample identity was then level in the position selected with reading accepted. The instrument was rotated to the position of the sample in the tray at $X$ - ray position after the start button was pressed while the intensity of radiation was now converted to the weight percentage.

\section{Extraction of Terminalia catappa Leaf Extracts (TCL)}

A $500 \mathrm{ml}$ soxhlet apparatus and ethanol as solvent was used for the extraction of Terminalia catappa leaf extract. A quantity $(100 \mathrm{~g})$ of the powdery sample was poured onto a Mushin cloth and placed inside the thimble of the apparatus. A round bottom flask containing $300 \mathrm{ml}$ of ethanol is fixed to the end of the apparatus and the condenser was tightly fixed at the bottom end of the extractor.

The whole set up is heated on a heating mantle at a temperature of $78^{\circ} \mathrm{C}$. The solvent was allowed to remain in contact with the powdery Terminalia catappa leaf extract sample for 3 hours and the excess solvent in the extract was recovered by heating.

\section{Experimental Procedure (Gravimetric Measurements)}

The effect of exposure time, inhibitor concentrations and temperatures was quantified using weight loss measurement. The corrosion study was carried out using the method described by Nwigbo et al. (2012). The mild steel coupons having dimensions of $2 \mathrm{~cm} \times 3 \mathrm{~cm} \times$ $0.12 \mathrm{~cm}$ were polished with abrasive paper, greased, degreased with ether of petroleum and thereafter rinsed with distilled water and dried. The mild steel coupon was suspended with the aid of a thread in $100 \mathrm{ml}$ beaker that contains $100 \mathrm{ml}$ of $1.5 \mathrm{M} \mathrm{HCl}$ Each coupon after corrosion study was inserted in distilled water and dipped in methanol solution, which was scrubbed to remove remaining acids, and residual inhibitor and thereafter dried in acetone before it was reweighed. The inhibition efficiency was calculate from Equation 1.

$$
E(\%)=\frac{W_{b}-W_{c}}{W_{b}} \times 100
$$

Where, $W_{b}$ is the weight loss in uninhibited medium (blank), and $W_{c}$ is the weight loss in inhibited medium.

\section{Statistical Analysis Experimental Design using}

The design expert software (Design - Expert 7.00) was used for the experimental design and modeling of experimental data. Seventeen (17) runs of experiments were generated with Box Behnken Design (BBD) as depicted in Table 2. The process variables studied were concentration of inhibitor $\left(X_{1}\right)$, time of exposure $\left(X_{2}\right)$, and temperature $\left(X_{3}\right)$ as shown in Table 1. 
Okewale: Effect of Terminalia catappa Leaves Extract on Corrosion of Mild Steel using Response...

Table 1: Box - Behnken design independent variables levels

\begin{tabular}{lclc}
\hline Independent variable & $\begin{array}{l}\text { Low } \\
\text { level }\end{array}$ & $\begin{array}{l}\text { Mid- } \\
\text { point }\end{array}$ & $\begin{array}{l}\text { High } \\
\text { level }\end{array}$ \\
\hline $\begin{array}{l}\text { Exposure time (hours) } \\
\text { Inhibitor concentration, }\end{array}$ & 3 & 6 & 9 \\
(g/L) & 0.1 & 0.3 & 0.5 \\
Temperature, (OC) & 35 & 45 & 55 \\
\hline
\end{tabular}

Table 2: Box-Behnken Design of Experiment plan (Actual Value)

\begin{tabular}{lll}
\hline $\begin{array}{l}\text { Time } \\
\text { (hours) }\end{array}$ & $\begin{array}{l}\text { Inhibitor } \\
\text { concentration } \\
\text { (g/L) }\end{array}$ & $\begin{array}{l}\text { Temperature } \\
\left({ }^{\circ} \text { C) }\right.\end{array}$ \\
\hline 6 & 0.5 & 55 \\
6 & 0.3 & 45 \\
6 & 0.1 & 55 \\
3 & 0.3 & 35 \\
9 & 0.1 & 45 \\
6 & 0.3 & 45 \\
6 & 0.5 & 35 \\
3 & 0.5 & 45 \\
6 & 0.1 & 35 \\
6 & 0.3 & 45 \\
6 & 0.3 & 45 \\
9 & 0.5 & 45 \\
3 & 0.1 & 45 \\
6 & 0.3 & 45 \\
9 & 0.3 & 55 \\
3 & 0.3 & 55 \\
9 & 0.3 & 35 \\
\hline
\end{tabular}

\section{Optimization of the RSM Regression Model}

The quadratic model generated from the Response Surface Methodology was optimized using the global response surface equation below;

$\mathrm{Y}=\beta_{0}+\sum_{i=1}^{k} \beta_{i} X_{i}+\sum_{i=1}^{k} \beta_{i i} X_{i}^{2}+$ $\sum_{i<j} \beta_{i j} X_{i} X_{j}+e(2)$

For three factor inputs of $x_{1}, x_{2}$ and $x_{3}$, the equation of the quadratic response is given as; $Y=b_{0}+b_{1} X_{1}+b_{2} X_{2}+b_{3} X_{3}+b_{12} X_{1} X_{2}+b_{13} X_{1} X_{3}+$ $b_{23} X_{2} X_{3}+b_{11} X_{1}{ }^{2}+b_{22} X_{2}{ }^{2}+b_{33} X_{3}{ }^{2}(3)$

$Y$ is the response predicted by the Response Surface Methodology, the linear coefficient is i and $j$ is the quadratic coefficients, regression coefficient is $\beta$, while parameters studied is $k$, and optimized in the experiment, and the random error is e (Ghorbana et al., 2008).

\section{RESULTS AND DISCUSSION Characterization of Mild Steel and Terminalia catappaleaf extract}

Table 3 shows the result of the $X$ - ray fluorescence of the mild steel used. It can be seen that iron has the highest percentage abundance.

Table 3: Result of the $\mathrm{X}-\mathrm{RF}$ Analysis on mild steel

\begin{tabular}{lc}
\hline Elements & Abundance (\%) \\
\hline Magnesium & 0.341 \\
Aluminium & 0.304 \\
Silicon & 0.190 \\
Sulphur & 0.065 \\
Chlorine & 0.031 \\
Calcium & 0.221 \\
Titanium & 0.125 \\
Chromium & 0.067 \\
Manganese & 0.203 \\
Iron & 98.362 \\
Cobalt & 0.061 \\
Bromine & 0.03 \\
\hline
\end{tabular}

Table 4 shows the presence of tannin, alkaloids, terpenoid, and saponins while the anthraquinone presence in the TCL leaf extract also suggest that the sample inhibit corrosion process of mild steel in acidic medium studied. The inhibitory action of this extract was attributed to the presence of organic compounds in their chemical constituents and the blocking of the metal surface via adsorption of these organic compounds onto the surface of metal in acidic solutions. The presence of these compounds has been reported to promote the corrosion inhibition of mild steel in aggressive acid media and also corroborating the works of other researchers (Prithiba et al., 2014; Owate et al., 2014; Umoren et al., 2006; Nwigbo et al., 2012). 
Table 4: Phytochemical Composition of TCL Extract

\begin{tabular}{lll}
\hline $\begin{array}{l}\text { Phytochemical } \\
\text { constituents }\end{array}$ & $\begin{array}{l}\text { Indicator } \\
\text { constituent } \\
\text { present }\end{array}$ & of \\
\hline Tannin & +++ \\
Saponin & +++ \\
Flavonoid & ++ \\
Alkaloid & +++ \\
Terpenoid & +++ \\
Phlobatannin & ++ \\
Anthraquinone & ++ \\
Cardiac glycosides & +++ \\
Reducing sugar & - \\
\hline
\end{tabular}

+++: More abundance, ++: Abundance, -: Absent

\section{Statistical Analysis of the Response Surface Methodology Quadratic Model of BBD}

Statistical testing of the quadratic model was done using analysis of variance (ANOVA) as depicted in Table 5. The significance of the model was adjudged by the $\mathrm{F}-$ value. The high $\mathrm{F}$ - value of 36.57 and $p$ - value $<0.0001$ showed the model is significant. Thus, the data obtained experimentally is represented well with the quadratic model. The standard deviation value of 2.87is realized. Coefficient of correlation $\left(R^{2}\right)$ value of 0.9792 which is closer to 1 was achieved for the model signifying that the predicted values are close to the actual values, suggesting that the model is accurate (Mohd and Rasyidah, 2010). The results from this investigation showed that the selected factors were sufficiently represented by the obtained model. This also described that there is an actual correlation among the factors selected in the experiment. It showed that $97.92 \%$ of the total variation in the inhibitor efficiency of TCL can be connected to the variables studied experimentally. The $p-$ values was used to check the significance of each coefficient in the model. An adequate precision ratio of 23.517 is achieved in this work which indicates an adequate signal. It can also be suggested that the model can be used to navigate the design space. Adequate signal for the model obtained was confirmed with the precision ratio value gotten. The goodness - of fit of the regression equation was measured using the adjusted determination of coefficient $\left(R^{2}\right)$.The predicted $R^{2}$ value of 0.888 , which indicates the model power in response prediction. The coefficient of variation (CV)for the standard deviation of the mean and experimental data is $3.91 \%$. It showed a better precision and reliability of the experiments carried out (Li et al., 2011; Rodrigues et al., 2012). This is less than $10 \%$ which is an indication that the data from the experiment is reproducible. The significance of each coefficient is also ascertained using the $\mathrm{P}$ value and $F$ - value at $5 \%$ confidence level. It can be seen that corrosion of mild using TCL as inhibitor was significantly affected by $\left(X_{2}\right.$, and $X_{3}$, $p<0.0001$ ) linear terms. It is obvious that the interaction terms $\left(X_{1} X_{3}\right.$, and $\left.X_{2} X_{3}\right)$ were also significant at the level of $p<0.05$ andthe quadratic terms $\left(X_{2}{ }^{2}\right.$, and $\left.X_{3}{ }^{2}\right)$ were also significant at the level of $p<0.05$. This allude an interaction between the process variables studied which were noted to be the core factors that affect the rate of corrosion, and weight loss of the mild which in turn affect the efficiency of the inhibitor. The Response Surface Methodology model for the corrosion inhibition of mild steel using TCL as an inhibitor was optimized using the desirability function of the Response Surface Methodology. The optimum conditions predicted from the quadratic model were inhibitor's concentratrion $(0.39 \mathrm{~g} / \mathrm{l})$, exposure time (8.68 hours), and temperature $\left(36.06^{\circ} \mathrm{C}\right)$ corresponding to the inhibitor's efficiency of $91.95 \%$. These values were validated with an average inhibitor's efficiency of $92.15 \%$ from three replicates and this was in agreement with the obtained optimum result predicted by the model. 
Okewale: Effect of Terminalia catappa Leaves Extract on Corrosion of Mild Steel using Response...

Table 5: ANOVA of regression equation for quadratic model

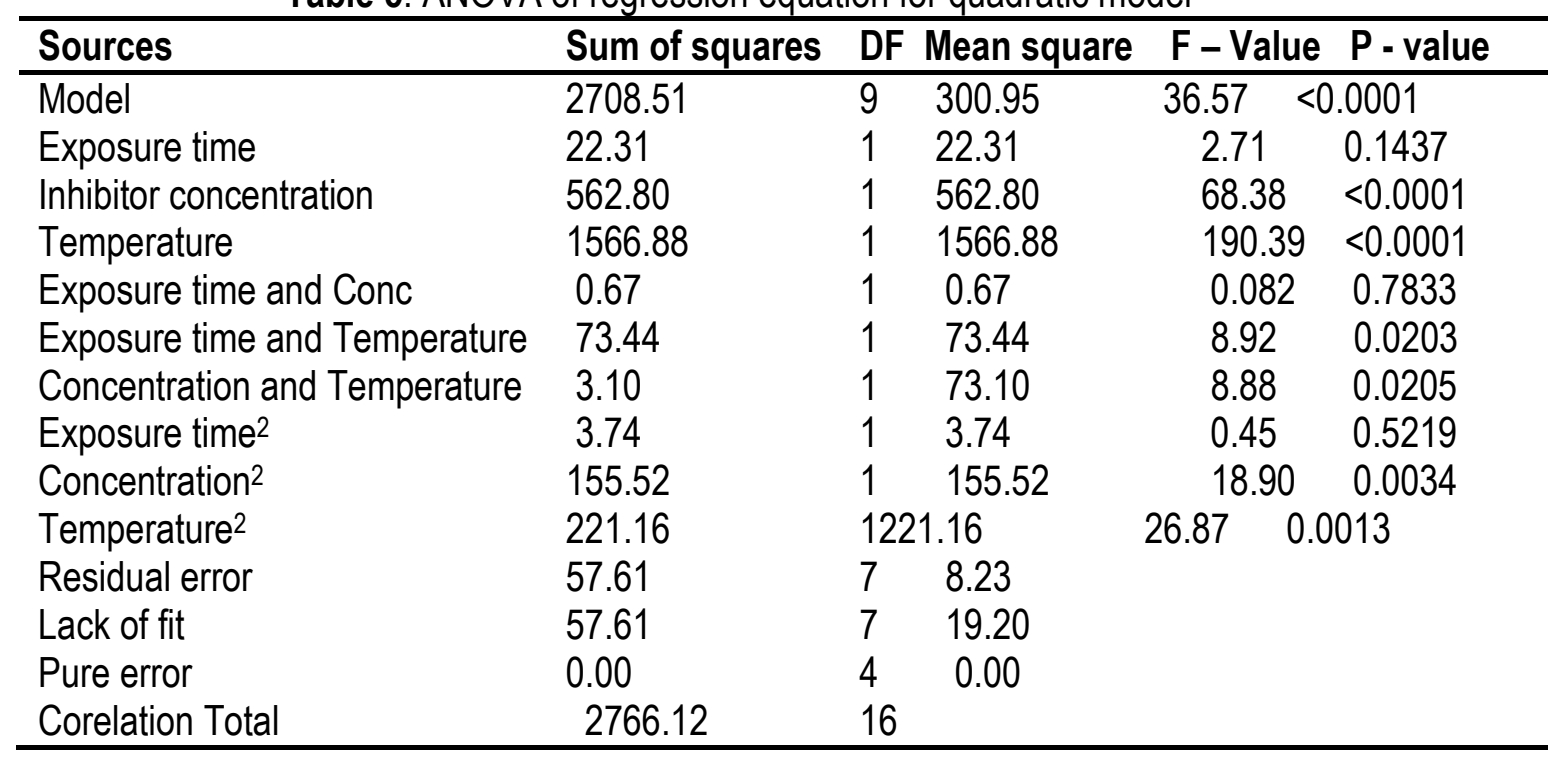

The experimental testing of full quadratic model is expressed by the second order polynomial equation in term of actual values is as follows: $Y=-45.52875+8.03583 x_{1}+32.81250 x_{2}+$ $5.33900 x_{3}+0.6833 x_{1} x_{2}-0.14283 x_{1} x_{3}+$ $2.1375 x_{2} x_{3}-0.10472 x_{1}{ }^{2}-151.93750 x_{2}{ }^{2}-$ $0.07247 x_{3}{ }^{2}(5)$

The final model equation after eliminating the insignificant terms is as follows;

$Y=-45.52875+2.81250 x_{2}+5.33900 x_{3}-$ $0.14283 x_{1} x_{3}+2.1375 x_{2} x_{3}-151.93750 x_{2}^{2}-$ $0.07247 x_{3}{ }^{2}(6)$

where, $Y$ is the inhibition efficiency, $x_{1}$ is exposure time (hr), $x_{2}$ is inhibitor concentration $(\mathrm{g} / \mathrm{L})$, and $\mathrm{x}_{3}$ is the temperature $\left({ }^{\circ} \mathrm{C}\right)$. The statistical estimate of the BBD obtained is shown in Table 6.

Table 6: Statistical estimates of BBD

\begin{tabular}{ll}
\hline Parameters & Value \\
\hline Standard deviation & 2.87 \\
Mean & 73.39 \\
Coefficient of variation $(\%)$ & 3.91 \\
Coefficient of determination $\left(\mathrm{R}^{2}\right)$ & 0.9792 \\
Predicted coefficient of determination & 0.888 \\
$\left(\mathrm{R}^{2}\right)$ & 0.9524 \\
Adjusted coefficient of determination $\left(\mathrm{R}^{2}\right)$ & 23.517 \\
Adequate precision & \\
\hline
\end{tabular}

The predicted and experimental data of the inhibition efficiency (\%) were also investigated to determine their correlation as depicted in Figure 1. The data points on the plot were moderately spread and very close to the straight line point. This suggests a sound connection between the predicted values and values obtained from the experiment for the response, and therefore the strong predictive power of the model. This further confirmed the assumptions made that the data is appropriate for the design space.

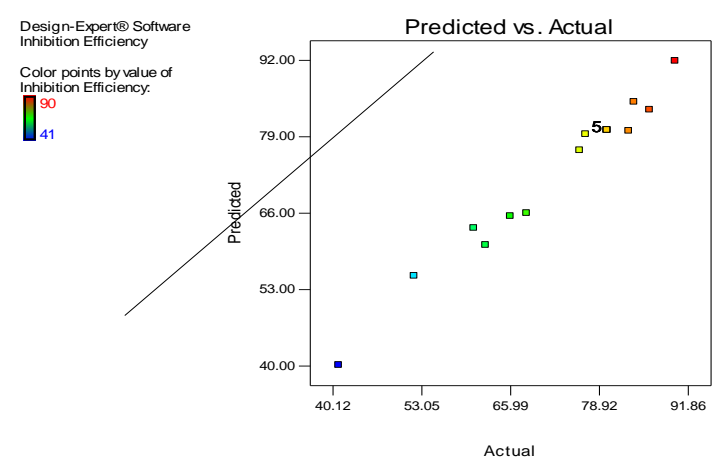

Figure 1: Predicted values of the model versus the experimental data values. 


\section{Surface Response Plots}

3-D surface response plots were presented in Figures $(2-4)$ based on the analysis of the full quadratic model.It was used to give an important evidence on the system behaviour within the experimental design on the corrosion of mild steel using TCL as an inhibitor. The different shapes of the contour plots indicated different interactions between the variables. An elliptical contour plot indicated interactions between the variables were significant while a circular contour plot means otherwise (Li-Chun Zhao et al., 2012).

Figure 2 contour plot showed an interaction between the concentration of an inhibitor and time of exposure on the efficiency of the corrosion inhibition. An increase in exposure time from 3 to Ghours enhanced the inhibition efficiency of the corrosion. Though, when time of exposure was increased more than 6hours, there was a steady decrease in the response but the inhibitor concentration over $0.4 \mathrm{~g} / \mathrm{L}$ did not indicate any effect that is evident on the efficiency of the corrosion inhibition. This can be explained that, increasing time of exposure may quicken the degradation of the bioactive chemical compound in the inhibitor, which lead to lower inhibition effeiciency.

Figure 3 described the effect of temperature $\left(x_{3}\right)$ and time of exposure $\left(x_{1}\right)$ on the corrosion inhibition efficiency, it can be seen that the inhibition efficiency is reduced as time of exposure is increased with temperature. This also affirmed the insignificant of the time of exposure in the model obtained from this study.

Figure 4 depicted the effect of temperature $\left(x_{3}\right)$, and inhibitor concentration $\left(\mathrm{x}_{2}\right)$, on the inhibition efficiency, it was observed that at lower temperature and inhibitor concentration favoured an increased in inhibition efficiency of the inhibitor on mild steel. This also confirmed the synergetic effect of these two terms on the inhibition efficiency.

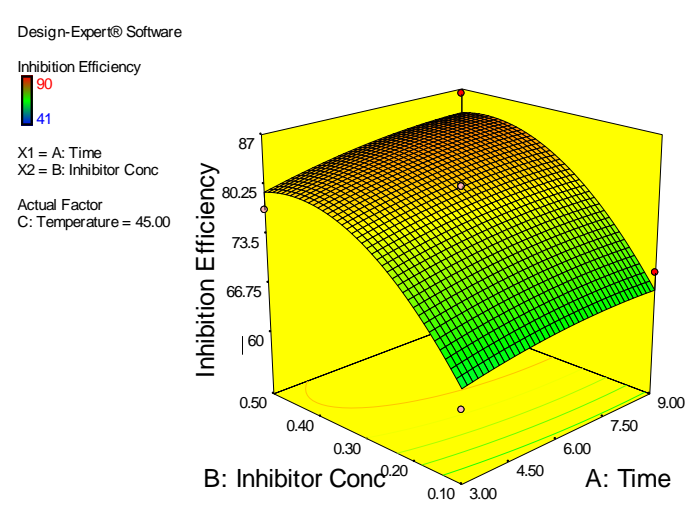

Figure 2: Surface Plot for the influence of inhibitor's concentration, time, and interface with efficiency of inhibitor.

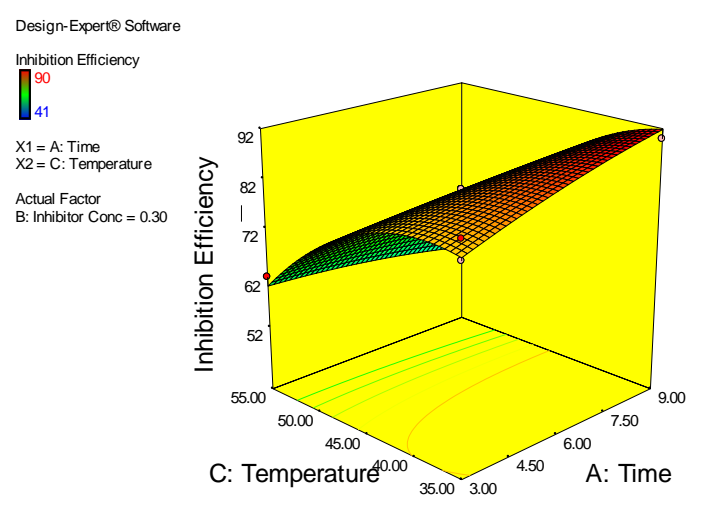

Figure 3: Surface plot for the influence of temperature, time, and interface with efficiency of inhibitor.

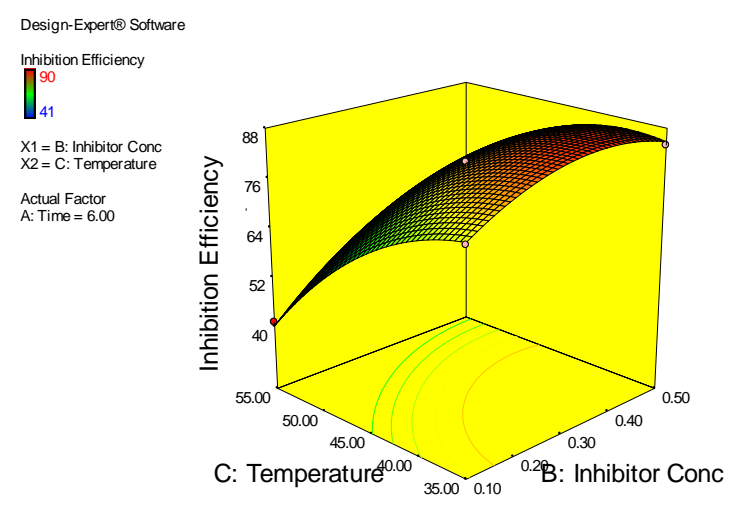

Figure 4: Surface plotfor the influence of temperature, inhibitor's concentration, and interface with efficiency of inhibitor. 


\section{Okewale: Effect of Terminalia catappa Leaves Extract on Corrosion of Mild Steel using Response...}

\section{CONCLUSION}

The corrosion inhibition of mild steel in acidic medium using TCL inhibitor can be linked to adsorption mechanism. The results showed that $97.92 \%$ of the total variation in the inhibition efficiency of TCL can be connected to the variables studied. The quadratic model developed showed that temperature and concentration of the TCL extract significantly affected the inhibition efficiency of the TCL extract on mild steel surface. Correlation coefficient of determination $\left(R^{2}\right)$ obtained was 0.9792 . The optimum process parameters obtained from the quadratic model developed were $0.39 \mathrm{~g} / \mathrm{L} \quad \mathrm{TCL}$ concentration,9hours immersion time, and temperature of $36.06^{\circ} \mathrm{C}$ with a predicted optimum inhibition efficiency value of $91.95 \%$. The results from the validated optimum value were in agreement with that predicted by the quadratic model.

\section{REFERENCES}

Bas, D. and Boyaci, I. H. (2007). Modeling and optimization 1: usability of response surface methodology.Journal of Food Engineering, 78: 836 - 845.

Bentiss, F., Traisnel, M. and Lagrenee, M. (2000). The substituted 1,3,4oxadiazoles: a new class of corrosion inhibitors of mild steel in acidic media.Corrosion Science, 42:127-146.

daRocha, J. C., Cunha, J. A., Gomes, P. and D'Elia, E. (2010). Corrosion inhibition of carbon steel in hydrochloric acid solution by fruit peel aqueous extracts. Corrosion Science, 52(7): 2341- 2348.

Eddy, N. O. and Odiongenyi, A. O. (2010). Corrosion inhibition and adsorption properties of ethanol extract of the insiacrinata on mild steel in $\mathrm{H}_{2} \mathrm{SO}_{4}$. Pigment and Resin Technology, 39(5): 288-295.

Ghorbana, F., Younesiaa, H. and Ghasempouria, S. M. (2008). Application of response surface methodology for optimization of cadmium bio-sorption in an aqueous solution by saccharomyces serevisiae.
Chemical Engineering Journal, 145: 267275.

Harborne, J. B. (1973). Phytochemical Methods, $3^{\text {rd }}$ ed., London, Chapman and Hall Ltd., ISSN 0412572605,135 - 203.

Hukovic-Metikos, M. Babic, R. and Grubac, Z. (2002). The study of aluminium corrosion in acidic solution with nontoxic inhibitors.Journal of Applied Electrochemistry, 32: 35 - 41.

Kalaiselvi, P., Chellammal, S., Palanichamy, S. and Subramanian, G. (2010).Artemisia pallens as corrosion inhibitor for mild steel in $\mathrm{HCl}$ medium.Material Chemistry Physics, 120: $643-648$.

Kamal, C. and Sethuraman, M.G. (2012). Pirulina pletensis- a novel green inhibitor for acid corrosion of mild steel. Arabian Journal of Chemistry, 5:155-161.

Li - Chun, Z., Ying, H., Xin, D., Geng - Liang, Y., Yang, W. L., and Jiang, L. (2012). Response surface modeling and optimization of accelerated solvent extraction of four lignans from fructus schisandrae.Molecules, 17, 3618 - 3629.

Li, W., Waang, Z. Sun, Y. S. Chen, L. Han, L. K. and Zheng, Y. N. (2011). Application of response surface methodology to optimize ultrasonic - assisted extraction of four chromones in radix saposhnikoviae, Phytochem. Analytical, 22: $313-321$.

Li, X., Deng, S. and Fu, H.(2010). Inhibition by Jasminum nudiflorum Lindl leaves extract of the corrosion of cold rolled steel in hydrochloric acid solution.Journal of Applied Electrochemical, 40:1641 1649.

Mohd, A. A. and Rasyidah, A. (2010). Optimization of malachite green by $\mathrm{KOH}$ - modified grape fruit peel activated carbon: Application of response surface methodology. The Chemical Engineering Journal, $751-988$.

Montgomery, D. C.(2001). Design and analysis of experiments, $5^{\text {th }}$ edition, John Wiley and 
Sons, New York, USA, ISSN 978-11814692-7, 200.

Nwigbo, S. C., Okafor, V. N. and Okewale, A. O. (2012). Comparative study of elaeis guiniensis exudates (Palm Wine) as a corrosion inhibitor for mild steel in acidic and basic solutions, Research Journal of Applied Science Engineering and Technology,4(9): 1035 - 1039.

Oguzie, E. E., (2008), Corrosion inhibitive effect and adsorption behaviour of Hibiscus sabdariffa on mild steel in acidic media Portugaliae ElectrochimicaActa, 26(3): 303-314.

Oguzie, E.E., Enenebeaku, C.K., Akalezi, C.O. Okoro, S.C. Ayuk,A.A. Ejike, E.N. 2010). Adsorption and corrosion-inhibiting effect of Dacryodis edulis extract on lowcarbon-steel corrosion in acidic media, Journalof Colloid Interface Science.349: 283-292.

Okafor, P. C., Ebenso, E. E. and Ekpe, U. J. (2010). Azadirachta indica extracts as corrosion inhibitor for mild steel in acid medium. International Journal of Electrochemical Science, 5: 973-998.

Okafor, P. C., Ikpi, M. E., Uwah, I. E., Ebenso, E. E., Ekpe, U. J. and Umoren, S. A. (2008). Inhibitory action of Phyllanthus amarus extract on the corrosion of mild steel in acid media.Corrosion Science, 50: 2310 $-2317$.

Okafor, P. C., Osabor, V. I. and Ebenso, E. E. (2007). Eco-friendly corrosion inhibitors: inhibitive action of ethanol extracts of garcinia kola for the corrosion of mild steel in $\mathrm{H}_{2} \mathrm{SO}_{4}$ solutions. Pigment Resin Technology, 36: 299 - 305.

Okewale, A. O., Igbokwe, P. K. and Adesina, O. A. (2015). Optimization of the adsorptive dehydration of ethanol-water system.Chemical and Process Engineering Research, 39: 27 - 37.

Okewale, A. O. and Olaitan, A. (2017). The use of rubber leaf extract as a corrosion inhibitor for mild steel in acidic solution.
International Journal of Materials and Chemistry, 7(1): $5-13$.

Okwu, D. E. (2001). Evaluation of the Chemical Composition of indigenous species and flavouring agents. Global Journal of Pure and Applied Science, 7(3): $455-459$.

Owate, I. O.,Nwadiuko, O. C., Dike, I. I., Isu, J. O. and Nnanna, L. A.(2014). Inhibition of Mild Steel Corrosion by Aspilia africana in Acidic Solution.American Journal of Materials Science, 4(3): 144-149.

Patela, N., Rawat, A., Jauhari, S. and Mehta, G. (2010). Inhibitive action of Bridelia retusa leaves extract on corrosion of mild steel in acidic media. European Journal Chemistry, 1:129 - 133.

Prithiba, A., Leelavathi, S. and Rajalakshmi, R. (2014). Application of natural products as corrosion inhibitors in different steel and media.Chemical Science Review and Letters,3: 177 - 187.

Quraishi, M. A., Singh, A., Singh, V. K., Yadav, D. K. and Singh, A. K. (2010). Green Approach to Corrosion Inhibition of Mild Steel in Hydrochloric Acid and Sulphuric Acid Solutions by the Extract of Murrayakoenigii Leaves. Materials Chemistry and Physics, 122(1):114 122.

Rahilla, T. N., Rukh, S. and Ziaidi, A. A. (1994). Phytochemical Screening of Medicinal Plants belonging to Euphoribiaceae. Pakistan Veterinary Journal, 14: $160-2$.

Raja, P. B. and Sethuraman M. G. (2008). Inhibitive effect of black pepper extract on the sulphuric acid corrosion of mild steel.Materials Letters, 62(17 - 18): 2977 $-2979$.

Raja, P. B. and Sethuraman, M. G. (2009). Solanumtuberosum as an inhibitor of mild steel corrosion in acid media. Iranian Journal of Chemistry and Chemical Engineering, 28(1), 77-84.

Raja, P. B., Rahim, A. A., Osman, H. and Awang, K. (2010).Inhibitory effect of Kopsia singapurensis extract on the corrosion 
Okewale: Effect of Terminalia catappa Leaves Extract on Corrosion of Mild Steel using Response...

behavior of mild steel in acid media. Acta Physica sinica, 26: 2171 - 2176.

Rodrigues, R. C. Kenealy, W. R. Dietrich, D. and Jeffries, T. W. (2012). Response surface methodology (RSM) to evaluate effects on corn stover in recovering xylose by DEO hydrolysis.Bioresource Technology, 108: 134-139.

Sharma, S. K., Mudhoo, A., Jain, G. and Sharma, J. (2010). Corrosion inhibition and adsorption properties of Azadirachta indica mature leaves extract as green inhibitor for mild steel in $\mathrm{HNO}_{3}$. Green Chemistry Letters and Reviews,3(1):7-5.

Singh, A. K. and Quraishi, M. A. (2010). Effect of cefazolin on the corrosion of mild steel in $\mathrm{HCl}$ solution.Corrosion Science, 52: 15260.
Sofowora, A. (1993). Medicinal Plants and Traditional Medicine in Africa, Ibadan, Nigeria, Spectrum Book Ltd., 289.

Umoren, S. A., Eduok, U. M., Solomon, M. M. and Udoh, A. P. (2016). Corrosion inhibition by leaves and stem extracts of sida acuta for mild steel in $1 \mathrm{M} \mathrm{H}_{2} \mathrm{SO}_{4}$ solutions investigated by chemical and spectroscopic techniques. Arabian Journal of Chemistry, 9: S209 - S224.

Umoren, S A. Ogbobe, O. Ebenso, E. E. and Ekpe, U. J(2006). Effect of halide ions onwell steels using organic inhibitors - A review: Journal of Material Environment Science, 3(5): 284-292. 